\title{
The Role of Emotion in Consumption
}

\author{
Jan P Voon ${ }^{1}$ \\ ${ }^{1}$ School of Economics, Faculty of Social Sciences, Lingnan University, Hong Kong \\ Correspondence: Jan P Voon, School of Economics, Faculty of Social Sciences, Lingnan University, 8 Castle \\ Peak Road, Tuen Mun, New Territory, Hong Kong. Tel: 852-2616-7175. E-mail: jvoon@ln.edu.hk
}

Received: June 11, 2013

Accepted: September 10, 2013

Online Published: October 26, 2013

doi:10.5539/ijef.v5n11p95

URL: http://dx.doi.org/10.5539/ijef.v5n11p95

\begin{abstract}
This paper develops and tests a model of consumption under uncertainty. The role of emotion is incorporated into the permanent income or life cycle theory of consumption (income-based model). An empirical test using structural equation modeling and China's consumer survey data $(\mathrm{N}=6993)$ showed that our consumption model with anticipatory feelings performed significantly better than pure income-based consumption models. Our results have practical application for policy formulation in China.
\end{abstract}

Keywords: emotion, financial crisis, consumption, structural equation modeling, China, policy

\section{Introduction}

This paper develops and tests an economic framework of consumption under uncertainty arising for instance from a global crisis. Under condition of uncertainty, behavior and decision pathways are subject to psychological influences (Caplin \& Leahy, 2001; Thaler, 1994; Shefrin \& Thaler, 1988; Tversky \& Kahneman, 1974). The past literature was largely devoted to examining how psychology could affect decision making, not consumption per se (see Kahneman, 2003). There is a paucity of studies on how psychology associated with an exogenous shock can affect consumption. According to the permanent income hypothesis, an exogenous shock gives rise to changes in current income and wealth as well as perceived future income which alters current consumption. An exogenous shock may also give rise to changes in psychological states which cause perceived future income to change. It is ironical that though the literature recognizes the importance of psychology, it was hardly incorporated for analytical purposes into the permanent income or life cycle model of consumption (see Carroll 2001 \& Deaton, 1992 for the reviews). The behavioral life cycle model of consumption advanced by Shefrin and Thaler (1988) also did not explicitly account for the mediating role of psychology.

Initially, we develop a general framework of household consumption (Figure 1). In this model, consumption decision is affected by three related factors: (i) income and wealth; (ii) psychological state; (iii) an exogenous shock. The permanent income theory postulates that an exogenous shock cannot affect consumption directly: income and wealth should be the main determining factor or mediator of consumption. Hence, pathway d in Figure 1 is not supported by the economic theory. There are three theory-backed routes by which consumption decision is affected by an exogenous shock (the theory is presented in the next section). Route 1: an exogenous shock may influence income and wealth (pathway $a_{1}$ ) before affecting consumption (pathway $\mathrm{a}_{2}$ ). In this case, income and wealth (or mental accounting) constitutes a mediator. (Note 1) This route corresponds to the permanent income or life cycle hypothesis but without any psychological state attached to it. Route 2: an exogenous factor may give rise to a psychological state (pathway $b_{1}$ ) before affecting consumption (pathway $b_{2}$ ). This channel is supported inter alia by the theory on bounded rationality originally advanced by Simon (1986). However, since this route omits income and wealth, it is not backed by the economic consumption theory. Route 3: an exogenous shock may first influence a psychological state (pathway $b_{1}$ ), which then influences income and wealth (pathway c) before affecting consumption (pathway $\mathrm{a}_{2}$ ). In this case, both mental accounting and psychological state are mediators crucial in influencing consumption. This route has not been empirically tested. 


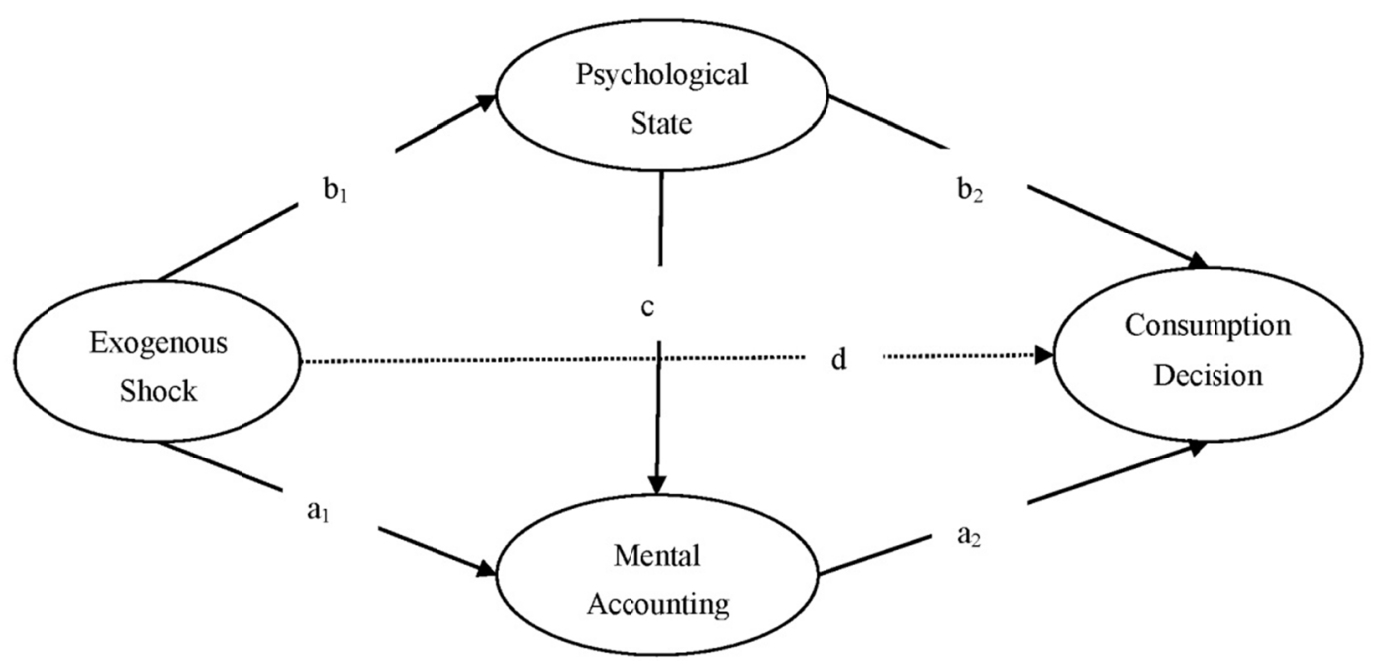

Figure 1. The theoretical model

In our empirical analysis, emotion (or anxiety as in Caplin and Leahy 2001) is used to represent a psychological state. The 2009 global financial crisis (GFC) is an example of exogenous shock. Our alternative model (route 3 above) is tested against the conventional income-based consumption model (route 1) using the Chinese household survey data collected during the GFC. Previously, empirical tests on new economic theories or models were often performed using regression analysis. However, regression analysis has a limitation for testing models with complex linkages across many variables. Given the deficiency of a regression analysis to capture the relationships across multiple mediators or linkages, it is crucial to develop and test the validity of our alternative model using the structural equation modeling (SEM) methodology. (Note 2) It is surprising that though SEM is very useful and popular for testing complex relationships, it is not widely used for model testing in economics.

In the following section, we review the different theories as they relate to the different pathways or routes depicted in Figure 1. Section III outlines the survey questionnaire and our data descriptions. Section IV presents our regression and SEM models and their empirical results. It also demonstrates the application of SEM for economic model testing. The conclusions and policy implications are given in the last section.

\section{Theoretical Reviews}

\subsection{The Permanent Income and Life Cycle Theory of Consumption $\left(a_{1}\right.$ and $\left.a_{2}\right)$}

In the past, several consumption frameworks with varying macroeconomic usages have been developed (Carroll, 2001). Early in development of consumption models, Keynesian formulation stipulates that consumption depends on current income only (without future income in the model). Accrued to the weakness of the household income hypothesis, the permanent income theory and the life cycle model were framed to explain consumption and consumer behavior. In such theoretical frameworks, consumption constitutes a type of decision on saving, so families consider future income and current income in order to stabilize their income over time. Several different types of permanent income and life cycle economic frameworks have appeared since the early development period (Deaton, 1992). For example, Hall (1978) developed a permanent income framework under condition of uncertainty, which includes precautionary saving, and Carroll (2001) came up with a buffer stock model to evaluate consumption under uncertainty.

\subsection{The Conservation of Resources Hypothesis $\left(b_{1}\right)$}

The basic tenet of the COR theory is that people have an innate as well as a learned drive to create, foster, conserve, and protect the quality and quantity of their resources (Hobfoll, 1989). These include tangible or material resources (such as shelter and possession) as well as intangible resources (such as emotional stability, psychological health, and self esteem). COR theory also postulates that personal resources affect each other and exist as a resource pool, and that lacking one is often associated with lacking the other (Hobfoll \& Shirom, 2000). Stress and insecurity occur when individuals' resources are threatened with loss, when individuals' resources are actually lost, or where individuals fail to gain sufficient resources following significant resource investment (Hobfoll, 2001). 
The COR theory is especially relevant in explaining the relationship between financial crisis and emotion. A financial crisis gives rise to real resource loss and threat of job loss. According to the COR theory, the actual loss of monetary resources and threat of employment loss give rise to loss of self esteem, depressive mood as well as employment-related distress (see also Hobfoll \& Shirom, 2000; Ünal-Karagüven, 2009).

\subsection{Emotion Heuristics $\left(b_{2}\right.$ and $\left.c\right)$}

Tversky and Kahneman (1974), Simon (1986), Thaler (1994) and Slovic (2005) posited that psychological tools are crucial in affecting economic decision making (e.g. mental accounting). When the economic is down, the economic surrounding may turn out to be quite uncertain, since we do not have objective information or immediate rational solution with us. The emotional pathways may be the major pathway influencing rational decision as the rational pathways may be incapacitated by lack of knowledge in what is happening, not able to control our circumstances or events, market breakdowns, or may be the reality that knowledge of a crisis is too complex or very hard to decipher. Under such a condition of uncertain times, people may just depend on emotional processes that entail making prompt emotional reactions..

Loewenstein (2001), Mellers and McGraw (2001), and Hammond (2000) suggest that psychology constitutes a crucial role in decision making. Emotions are important factors for changing a thinker into a person who take an action (Frijda, Manstead and Bern 2001). The significance of emotion/psychology in making economic decision was also shown in Kahneman (2003) who recognize the difference between emotional pathways and rational thinking. Chaudhury (2006) demonstrates that emotion reactions may mediate for economic behavioral responses. Finucane et al. (2000) found that psychology or human emotion may usually streamline decision processes.

\subsection{An Alternative Model $\left(b_{1}, c\right.$ and $\left.a_{2}\right)$}

Our alternative framework which considers emotion is an overall structure framework as shown by paths $b_{1}, c$ and $a_{2}$ in Figure 1. It is a permanent income or life cycle model because income and wealth are still the primary determinants of consumption and the importance of mental accounting between current and future income changes is considered. The model as a whole has a wider perspective, or one which reflects the real life situation, because the possible emotional influence is embraced in the model. The framework is not just used for evaluating consumption under economic down times. For example, exogenous shocks could also give rise to positive emotions and irrational exuberance such as during periods of stock market boom. When exogenous shocks alter consumers' psychological states, decisions might be taken through emotional means whereby people are exposed to intuition, or psychological or emotional processes.

\section{The Data}

The dataset was collected from a household survey administered by China's Statistical Bureau in August 2009. 6993 of 10043 samples were included in our analysis, while 3099 were deleted for their unemployment status. A translated copy of the survey questionnaires are shown in Table 1.

Table 1. Summary of translated questionnaires

\begin{tabular}{|c|c|c|c|c|c|}
\hline Consumption & Reduced & & No Change & & Enhanced \\
\hline $\begin{array}{l}\text { Relative to before the global financial crisis, does any } \\
\text { change happen to your daily consumption? }\end{array}$ & 1 & 2 & 3 & 4 & 5 \\
\hline Crisis Information & \multicolumn{3}{|c|}{ No Influence } & \multicolumn{2}{|c|}{ Large Influence } \\
\hline \multicolumn{6}{|c|}{ When evaluating the global financial crisis, to what degree are you affected by the following information? } \\
\hline Employment Decline & 1 & 2 & 3 & 4 & 5 \\
\hline Retrenchment/Layoff & 1 & 2 & 3 & 4 & 5 \\
\hline Emotion Constructs & \multicolumn{3}{|c|}{ Very Much Disagree } & \multicolumn{2}{|c|}{ Very Much Agree } \\
\hline \multicolumn{6}{|c|}{ Here are some statements about the global financial crisis. To what extent do you agree with each? } \\
\hline You feel uneasy & 1 & 2 & 3 & 4 & 5 \\
\hline You feel worried or anxious & 1 & 2 & 3 & 4 & 5 \\
\hline You feel fearful & 1 & 2 & 3 & 4 & 5 \\
\hline Mental Accounting & Reduced & & No Change & & Enhanced \\
\hline \multicolumn{6}{|c|}{ Relative to before the global financial crisis, did any change happen to you on the following aspects? } \\
\hline Wealth & 1 & 2 & 3 & 4 & 5 \\
\hline Current and Future Income & 1 & 2 & 3 & 4 & 5 \\
\hline
\end{tabular}


About half of our sample employed workers (69 percent) arose from relatively poor places/provinces. About 31 per cent originated from richer states such as Beijing, Shanghai, and Guangdong. About 54 per cent were employed by state-owned companies and about 46 per cent were employed by private enterprises. About 72 per cent were males and 28 per cent were females. The age of those whom we surveyed was from 22 to 74 (Average of about 44, Standard Deviation of about 9). A little more than 90 per cent were married and the remaining were single or divorced. The mean employment experience was about 23 years (Standard Deviation of about 10). Nearly half of those we surveyed (roughly 40 per cent) held university/college or tertiary standard. The mean income of the employed was approximately 19810 yuans (Standard Deviation of 18070), about 65 per cent of them have lower than average incomes.

The 2009 global finance meltdown is shown by 2 items, that is, decline in employment and corporate/company discharge/layoff. Those we surveyed were requested by us to show the extent to which they were influenced by the above items/cases when evaluating the global financial meltdown in 2009. The scale is from one (1) to five (5), and the more the scoring, the more one is influenced. On emotional side, 3 items, namely, uneasiness, anxiety and fear, were made use of on a five point scale. The lower score shows one was not adversely affected by the crisis but the highest score represents that they were greatly affected. To assess mental accounting, we develop some questionnaires using 5-point scale. The higher scoring corresponds to higher income/wealth. Scoring of three indicates that there was no change at all. In structuring our questions, we asked those whom we surveyed their current plus future alterations in income, therefore allowing for mental accounting to occur. Mental accounting is an important consideration in emotion heuristics. The final factor in our survey is consumption. Merely one item was used to indicate household consumption during the GFC. We again employed five point scale: higher score corresponds to higher consumption.

For examining how the 2009 global financial crisis influenced daily consumption, we purposely developed the questions for our survey by permitting the Global financial crisis to be one period prior to consumption by allowing our questions to exhibit time lag. For instance, "Comparing to when the financial crisis has not yet happened, how would your current consumptions change?" This allows us to have causality for our data assessment in this paper.

\section{Empirical Analysis}

\subsection{Regression Models and Results}

A regression model has been developed for assessing how the consumption is related to the three independent variables: crisis information; emotion; and mental accounting. The model is written as:

$$
C_{j}=a+\sum_{i=1}^{2} \alpha_{i} I_{i j}+\sum_{i=1}^{3} \beta_{i} E_{i j}+\sum_{i=1}^{2} \gamma_{i} M_{i j}+\sum_{i=1}^{12} \lambda_{i} P_{i j}+\varepsilon_{j}
$$

where subscript $i$ denotes item within each category of the independent variable and subscript $j$ denotes respondent $j . I, E, M$ and $P$ denotes, respectively, information about the crisis, emotion, mental accounting and the province dummies. In our regression, both the province cluster and dummy variables were used for the control of heterokedasticity across provinces.

Table 2 showed that the GFC, indicated by employment decline and corporate layoff, was not significant in affecting the consumption directly. These results point to the importance of the income-based permanent income theory. Our results also showed that emotion, especially anxiety, often a concomitant outcome of a financial crisis, was a significant variable affecting the consumption. Anxiety, arising from a chain of negative unemployment and retrenchment information arising from the GFC, reduced the total consumption. This result points to the importance of emotion, specifically anxiety, in influencing consumption. It also seems at this juncture to point out the inadequacy of a pure income-based model of consumption. Caplin and Leahy (2001), in their theoretical proposition, also outlined the role of anticipatory feeling (specifically anxiety) in affecting decision. 
Table 2. Effects of GFC, emotion and mental accounting on consumption: ordered logit versus ordered probit $(\mathrm{N}=6993)$

\begin{tabular}{|c|c|c|c|c|}
\hline Categorized IV & Itemized IV & Ordered Logit & Ordered Probit & VIF \\
\hline \multirow{2}{*}{$\begin{array}{l}\text { Crisis Information } \\
\text { (C) }\end{array}$} & Employment Decline & $-.032(.028)$ & $-.023(.015)$ & \multirow{2}{*}{2.22} \\
\hline & Retrenchment/Layoff & $.019(.029)$ & $.018(.016)$ & \\
\hline \multirow{4}{*}{$\begin{array}{l}\text { Emotion } \\
\text { (E) }\end{array}$} & Uneasy & $-.027(.037)$ & $-.011(.021)$ & 1.62 \\
\hline & Anxiety & $-.088(.043)^{* *}$ & $-.056(.025)^{* *}$ & 1.96 \\
\hline & Fear & $.051(.046)$ & $.030(.027)$ & 1.76 \\
\hline & Wealth & $.089(.038)^{* *}$ & $.041(.023)^{*}$ & \\
\hline \multirow{8}{*}{$\begin{array}{l}\text { Mental Accounting } \\
\text { (M) }\end{array}$} & [Marginal Effect] & {$[.0026]$} & {$[.0011]$} & 1.57 \\
\hline & Income & $.546(.036)^{* * *}$ & $.286(.021)^{* * *}$ & 1.55 \\
\hline & $\begin{array}{l}\text { [Marginal Effect] } \\
\text { Pro } 1 \text { (Beiiing) }\end{array}$ & {$[.0156]$} & {$[.0078]$} & 128 \\
\hline & $\begin{array}{l}\text { Pro_1 (Beijing) } \\
\text { Pro_2(Tianjin) }\end{array}$ & $\begin{array}{l}-.183(.128) \\
-.093(.126)\end{array}$ & $\begin{array}{l}-.119(.063)^{4} \\
-.056(.063)\end{array}$ & 1.23 \\
\hline & Pro $\overline{3}$ (Shanghai) & $.394(.129) * * *$ & $.210(.065)^{* * *}$ & 1.36 \\
\hline & Pro_4(Jiangsu) & $.001(.124)$ & $.002(.062)$ & 1.14 \\
\hline & Pro_5(Zhejiang) & $.063(.125)$ & $.031(.063)$ & 1.39 \\
\hline & Pro_6(Fujian) & $-.065(.127)$ & $-.037(.064)$ & 1.48 \\
\hline \multirow{8}{*}{$\begin{array}{l}\text { Dummy Coding } \\
\text { (D) }\end{array}$} & Pro_7(Guangdong) & $-.280(.123)^{* *}$ & $-.151(.061)^{* *}$ & 1.42 \\
\hline & Pro_8(Inner Mongolia) & $-.293(.129) * *$ & $-.160(.066)^{*}$ & 1.21 \\
\hline & Pro_9(Heilongjiang) & $-.251(.124)^{* *}$ & $-.119(.061)^{*}$ & 1.16 \\
\hline & Pro_10(Anhui) & $-.194(.125)$ & $-.116(.063) *$ & 1.24 \\
\hline & Pro_11(Hubei) & $-.146(.125)$ & $-.081(.062)$ & 1.28 \\
\hline & Pro_12(Hunan) & $-.016(.126)$ & $-.026(.063)$ & 1.29 \\
\hline & Pro_13(Guangxi) & $-.114(.125)$ & $-.068(.062)$ & 1.19 \\
\hline & Pro_14(Yunnan) & $-.168(.121)$ & $-.066(.060)$ & 1.14 \\
\hline
\end{tabular}

Note: ${ }^{*} \mathrm{p}<.10,{ }^{* *} \mathrm{p}<.05, * * * \mathrm{p}<.01$.

Consumption was found to be highly significantly correlated to changes in household income and, to a lesser extent, wealth. This verifies the validity of the permanent income theory originally advanced by Friedman. In this paper, the current and future incomes were measured together as one variable and wealth was measured as another separate variable. Consistent with the BLC theory proposed by Shefrin and Thaler (1988), we observe a very high propensity of consumption with respect to income but relatively lower propensity of consumption with respect to wealth.

\subsection{SEM Models and Results}

Regression models examine how each independent variable directly affects a dependent variable immediately preceding it. It cannot be used to test between models with multiple linkages across variables. For example, the linkages across $b_{1}, c$, and $a_{2}$ cannot be conveniently tested. For our paper, SEM is employed for testing different/alternative frameworks using diagrammatic illustration. SEM is employed to find out the statistical correctness of complicated structure frameworks by fitting the models to our available data used in this research.

The alternative structure framework has 4 latent variables: GFC, emotion, (MA) mental accounting, as well as consumption. For the structure framework, GFC is indicated by 2 items, that is, employment decline and corporate or company layoff or discharge; emotion is shown by 3 items, namely, uneasiness, anxiety and fear; MA is indicated both by current as well as future perceived income/wealth; and lastly, consumption is a one item only variable. These 4 latent variables and the corresponding assessable items are knitted together in our structural framework as presented in Figure two. The shape of an oval shows a latent variable and the shape of a rectangle shows an assessable item/construct. The cause-and-effect causal relations are shown by the arrow keys. All our fit results/statistics and pathway coefficients were generated using Lisrel version 8.51. 


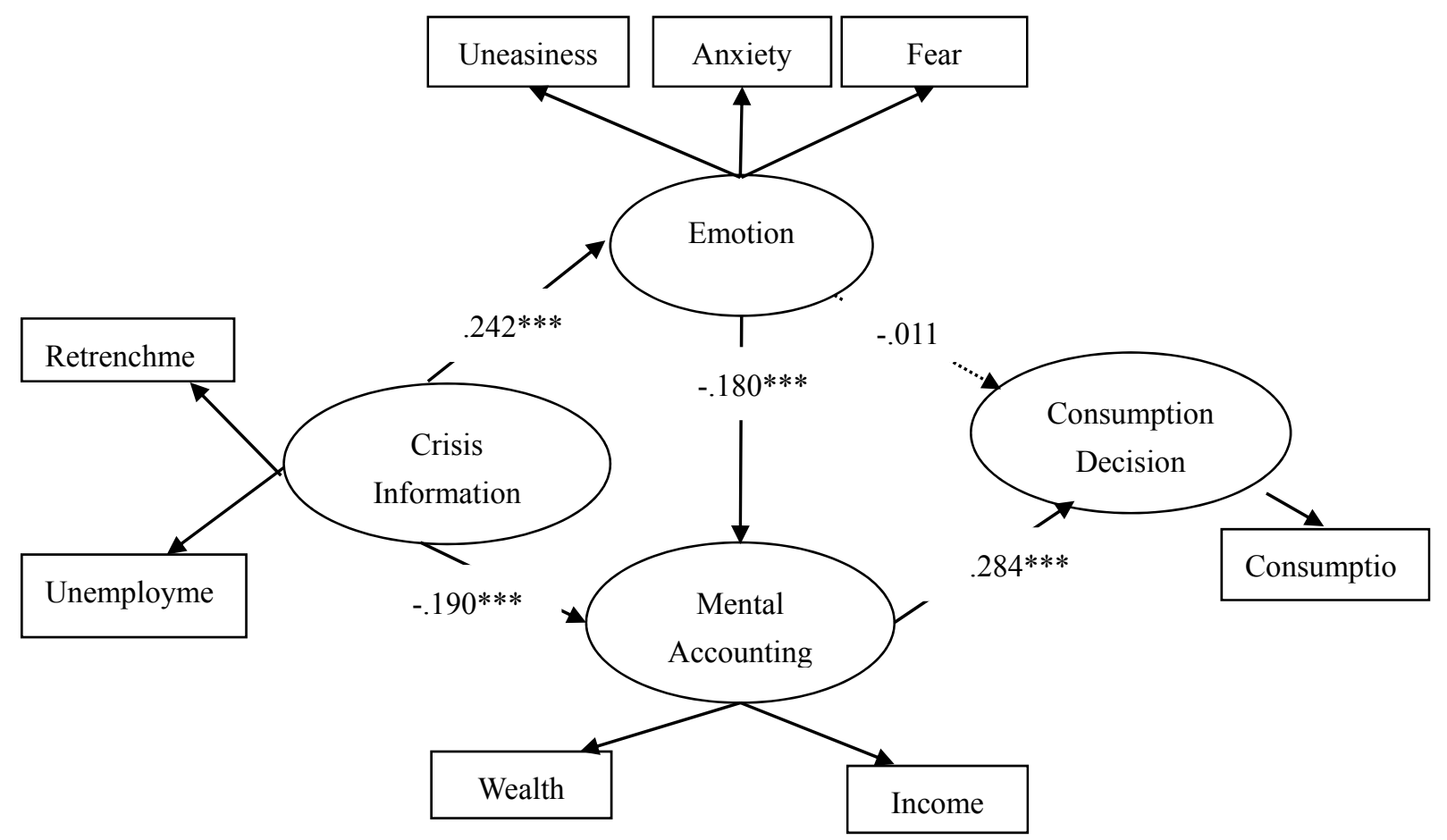

Figure 2. Model 1 path coefficients

The fit statistics of our structural model in SEM are presented in Table 3. We observe that the model fitted the data very well. For example, most of the p-values were non-significant $(p>0.05)$ and $C F I, N F I$ larger than 0.9 , and RAMSEA smaller than 0.05 . The model fitness became even more pronounced when the whole dataset is segregated into smaller subsamples differentiated by the provinces (see Table 3). Notably, the p-values became even more insignificant.

Table 3. Fit indexes for whole data set and province subsamples

\begin{tabular}{|c|c|c|c|c|c|c|c|}
\hline & Sample & $\chi^{2}$ & $d f$ & $P$ & CFI & NFI & RMSEA \\
\hline Whole data & 6993 & 57.56 & 16 & .000 & .997 & .997 & .019 \\
\hline \multicolumn{8}{|c|}{ Relatively rich provinces } \\
\hline Beijing & 425 & 22.22 & 16 & .136 & .993 & .977 & .030 \\
\hline Tianjin & 336 & 15.29 & 16 & .504 & 1.000 & .984 & .000 \\
\hline Shanghai & 560 & 19.70 & 16 & .234 & .997 & .986 & .020 \\
\hline Jiangsu & 200 & 22.51 & 16 & .127 & .986 & .955 & .045 \\
\hline Zhejiang & 597 & 14.64 & 16 & .551 & 1.000 & .990 & .000 \\
\hline Fujian & 782 & 31.29 & 16 & .012 & .991 & .983 & .035 \\
\hline Guangdong & 662 & 25.83 & 16 & .057 & .993 & .982 & .030 \\
\hline \multicolumn{8}{|c|}{ Relatively poor provinces } \\
\hline Inner Mongolia & 310 & 26.14 & 16 & .052 & .989 & .971 & .045 \\
\hline Heilongjiang & 236 & 30.61 & 16 & .015 & .976 & .951 & .062 \\
\hline Anhui & 362 & 11.95 & 16 & .748 & 1.000 & .986 & .000 \\
\hline Hubei & 421 & 19.47 & 16 & .245 & .995 & .976 & .023 \\
\hline Hunan & 437 & 24.02 & 16 & .089 & .993 & .979 & .034 \\
\hline Guangxi & 283 & 16.63 & 16 & .410 & .999 & .979 & .012 \\
\hline Yunnan & 204 & 32.45 & 16 & .009 & .948 & .911 & .071 \\
\hline
\end{tabular}


The individual path coefficients are shown in Table 4. Consistent with the income-based consumption theories, $a_{1}$ and $a_{2}$ were verified to be significant. $b_{1}$ was significant, supporting the COR theory as it relates to financial crisis. $b_{2}$ was observed to be insignificant, contrary to our regression result. It is of interest that path $\mathrm{c}$ was significant, verifying the importance of our alternative consumption pathway (route 3). Our results were consistent across majority of the provinces.

Table 4. Path coefficients for whole data set and province subsamples

\begin{tabular}{clllll}
\hline \multicolumn{7}{c}{ Path $\mathrm{a}_{1}$} & Path $\mathrm{a}_{2}$ & Path $\mathrm{b}_{1}$ & Path $\mathrm{b}_{2}$ & Path c \\
\hline Rhole data & \multicolumn{7}{c}{ Relatively rich provinces } \\
Beijing & $-.369^{* * *}$ & $.271^{* * *}$ & $.240^{* * *}$ & .006 & -.117 \\
Tianjin & $-.300^{* * *}$ & $.390^{* * *}$ & $.243^{* * *}$ & -.046 & $-.125^{*}$ \\
Shanghai & $-.138^{* *}$ & $.256^{* * *}$ & $.353^{* * *}$ & .053 & $-.212^{* * *}$ \\
Jiangsu & -.094 & $.331^{* * *}$ & $.307^{* * *}$ & .013 & $-.223^{* *}$ \\
Zhejiang & $-.135^{* *}$ & $.244^{* * *}$ & $.262^{* * *}$ & .061 & $-.170^{* * *}$ \\
Fujian & $-.206^{* * *}$ & $.356^{* * *}$ & $.242^{* * *}$ & -.018 & $-.181^{* * *}$ \\
Guangdong & $-.237^{* * *}$ & $.273^{* * *}$ & $.281^{* * *}$ & .044 & $-.204^{* * *}$ \\
Relatively poor provinces \\
Inner Mongolia & $-.331^{* * *}$ & $.232^{* * *}$ & $.292^{* * *}$ & -.051 & $-.239^{* * *}$ \\
Heilongjiang & $-.159^{*}$ & -.068 & $.227^{* *}$ & .020 & $-.300^{* * *}$ \\
Anhui & $-.152^{* *}$ & $.325^{* * *}$ & $.196^{* *}$ & .030 & $-.286^{* * *}$ \\
Hubei & -.103 & $.268^{* * *}$ & $.200^{* *}$ & -.050 & $-.152^{*}$ \\
Hunan & $-.145^{* *}$ & $.202^{* * *}$ & .083 & $-.139 * *$ & $-.211^{* * *}$ \\
Guangxi & .054 & $.446^{* * *}$ & $.246^{* * *}$ & -.036 & $-.217^{* *}$ \\
Yunnan & -.177 & $.210^{* * *}$ & $.269^{* * *}$ & -.079 & -.041 \\
\hline \multicolumn{7}{c}{}
\end{tabular}

Table 4 showed that when path $\mathrm{c}$ was omitted, the structural model did not fit the data as well as with path $\mathrm{c}$ intact, as judged by the $\Delta \chi^{2} / \Delta d f$ criterion. Path $\mathrm{c}$ therefore constitutes an important but missing link in the model. Hence, if the GFC generated anxiety and threat of job insecurity (according to the COR theory), the worker would perceive his or her future income and wealth to decline (emotion heuristics) which then lowers his or her current consumption (consistent with the income hypothesis). Emotion provides a very important role in mediating the effect of an exogenous shock on household consumption.

Table 5. Alternative model comparison: fit indexes and path coefficients

\begin{tabular}{cccccccc}
\hline & $\chi^{2}$ & $d f$ & $P$ & CFI & NFI & RMSEA & $\Delta x^{2} / \Delta d f$ \\
\hline Model 1: full model & 57.56 & 16 & .000 & .997 & .997 & .019 & \\
Model 2: without path c & 191.64 & 17 & .000 & .989 & .988 & .038 & $134.08 / 1^{* * *}$ \\
Model 3: without path $\mathrm{b}_{2}$ & 57.94 & 17 & .000 & .997 & .996 & .019 & $0.38 / 1$ \\
& $\mathrm{a}_{1}$ & $\mathrm{a}_{2}$ & $\mathrm{~b}_{1}$ & $\mathrm{~b}_{2}$ & $\mathrm{c}$ \\
Model 1: full model & $-.190^{* * *}$ & $.284^{* * *}$ & $.242^{* * *}$ & -.011 & $-.180^{* * *}$ \\
Model 2: without path c & $-.234^{* * *}$ & $.280^{* * *}$ & $.248^{* * *}$ & $-.023^{*}$ & \\
Model 3: without path $\mathrm{b}_{2}$ & $-.190^{* * *}$ & $.287^{* * *}$ & $.242^{* * *}$ & & $-.181^{* * *}$ \\
\hline
\end{tabular}

We also test the fitness of the model when $b_{2}$ was dropped from the original model (see Table 5). Using the SEM methodology, the model without $b_{2}$ (see Figure 3 ) was shown to be better than the original model $\left(w i t h b_{2}\right)$, as shown by the $\Delta \chi^{2} / \Delta d f$ criterion. Our model presented in Figure 3 shows that a pure income-based consumption model (Route 1) is important but inadequate to explain the changes in consumption originating from the GFC. In this paper, we show that route 3, with emotion generated from the GFC as a precursor, was an alternative consumption model. 


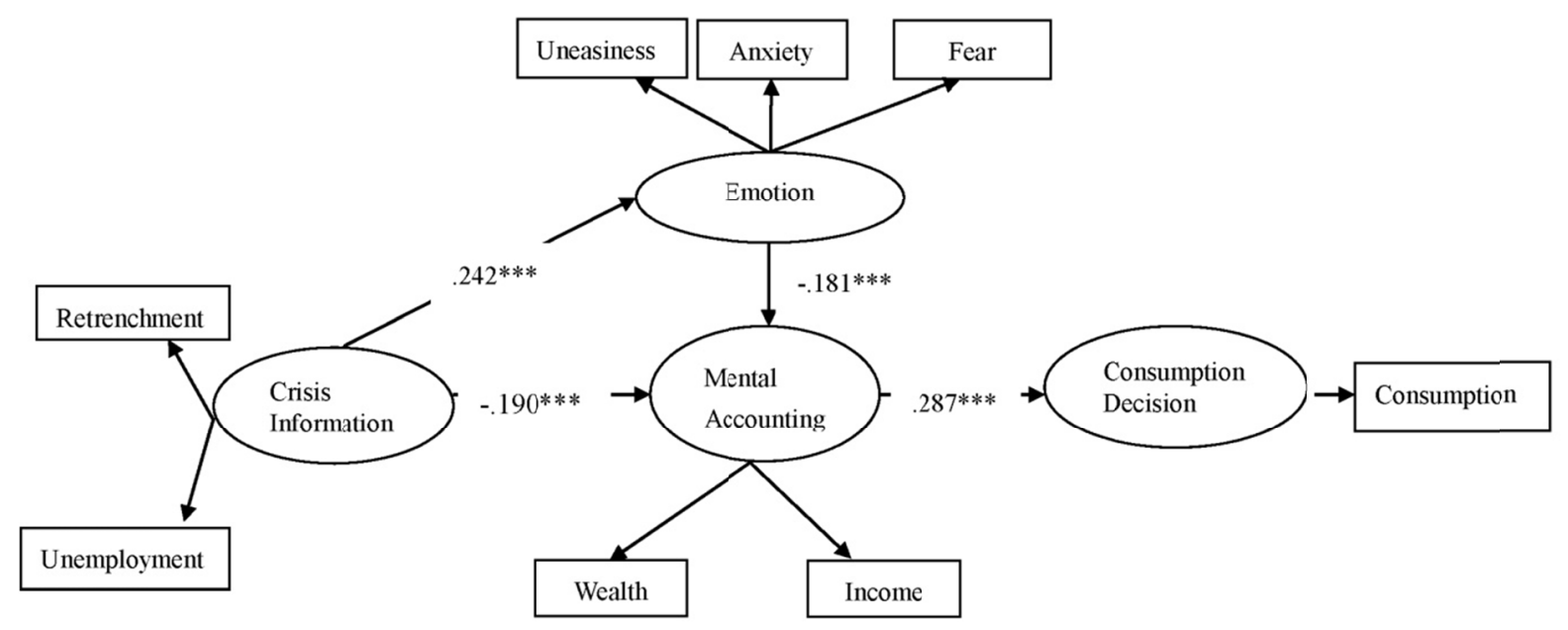

Figure 3. Model 3 path coefficients

Our paper also demonstrates the practical importance of SEM for testing structure frameworks. It is better than regression analysis if complicated models are involved. It shows the usefulness for applying SEM to structural economic modeling. So far, SEM is often employed in disciplines other than economics. This paper demonstrates that SEM is very useful for testing complicated economic relationships.

\section{Conclusions and Policy Implications}

Our research shows that changes in household incomes were not only directly affected by the rational events or developments due to the financial crisis but also indirectly affected by psychological states or in the case of our paper negative emotional states arising from the GFC. The traditional economic consumption modeling by itself could not sufficiently explain the changes in consumption in the absence of psychologically related structural relationships. Because China is currently the second largest economy in the world, and China has become more and more knitted with the international market, the global financial crisis and global negative spillovers could not be easily averted. Therefore, it is very important to find practical ways to reduce undesirable influences emanating from economic recession.

Unlike the United States or some countries in Europe, welfare payments and public assistance from the governments are rare in China. It is good for China to implement more saving methods/schemes, old age pension funds, temporary government relief measures and practical government policies, particularly during an economic crisis. These income-protecting measures work to reduce any decline in household consumption via the reduction in negative emotional wellbeing. Measures could be implemented to reduce reduction in employment/layoff/discharge. This again helps to allay fears or negative emotional states associated with the economic downturn.

The GFC results in a global shortfall of demand. As a result, the global economy seems to be relying on China, with its huge consumption market, to absorb some of the excess demand. In order to help the world, China must first be able to stimulate its own domestic consumption which comprises domestic and imported goods and services. This paper, however, shows that the domestic consumption was negatively affected by the financial crisis. Current domestic consumption could be reduced by reductions in perceived future incomes. Hence, a decline in consumption or a lack of effective measures to counter the decline in consumption means that China was not able to soak up domestic production, implying that China might not be in a favorable position to help the global economy to recover.

Another implication lies in the economic relations between two of the dominant economies in the world today (US and China), which epitomize the sources and dangers of global macroeconomic imbalances. China's exports to the US rose from $\$ 100$ billion in 2000 to $\$ 338$ billion in 2008 , while imports rose from $\$ 16$ billion to $\$ 71$ billion (Chinese Statistical Year Book 2009). The Sino-US trade imbalances have ballooned in recent years. There has been some debate about whether global macroeconomic imbalances were the proximate cause of the GFC, as global imbalances allowed problems in the US financial system to fester and end in a cataclysm. 
Available statistics portray that private consumption in China has not been a key driver of growth. Hence, it is of paramount importance for China to expand its domestic consumption of domestic and foreign goods and services.

Incidentally, the high domestic saving rates relative to the low US saving rates might also have contributed to Sino-US trade imbalance (Modigliani \& Cao, 2004). This paper sheds light on the rationale for high saving rates in China during the GFC. First, we observe that since the onslaught of the GFC, the saving rates of the Chinese rose faster than that of the US, contributing to more imbalances (Chamon \& Prasad, 2008). Second, the rise in domestic saving rates could be attributed to unfavorable heuristic assessments of their future incomes due to job insecurity related to the GFC. An implication is that compelling China to revalue its RMB vis-à-vis the US dollar may not redress the Sino-American trade imbalance unless domestic consumption could be substantially expanded by addressing some of the pertinent issues raised in this paper.

\section{Acknowledgements}

This research was supported by a research grant from Lingnan University (Grant Number DR09D4). I also thank Nancy Zhang of Peking University for her research assistance.

\section{References}

Allen, F., \& Gale, D. (2007). Understanding financial crisis. Oxford: Oxford University Press.

Bollen, K. A., \& Davis, W. R. (2010). Causal indicator models identification, estimation and testing. Structural Equation Modeling.

Byrne, B. M. (2010). Structural equation modeling with AMOS: Basic concepts, applications, and programming (2nd ed.). New York: Taylor and Francis.

Caplin, A., \& Leahy, J. (2001). Psychological expected utility theory and anticipatory feelings. Quarterly Journal of Economics, 116, 55-79. http://dx.doi.org/10.1162/003355301556347

Carroll, C. D. (2001). A theory of consumption function with and without liquidity constraints. NBER Working Papers, No. 8387.

Chamon, M., \& Prasad, E. S. (2008). Why are saving rates of urban households in China rising? NBER Working Paper, No. 14546.

Chaudhury, A. (2006). Emotion and reason in consumer behavior. Butterworth-Heinemann.

Deaton, A. (1992). Understanding consumption. Oxford University Press. http://dx.doi.org/10.1093/0198288247.001.0001

Finucane, M. L., Alhakami, A., Slovic, P., \& Johnson, S. M. (2000). The affect heuristics in judements of risks and benefits. Journal of Behavioural Decision Making, 13, 1-17. http://dx.doi.org/10.1002/(SICI)1099-0771(200001/03)13:1<1::AID-BDM333>3.0.CO;2-S

Frijda, N., Manstead, H., Anthony, S., \& Bem, S. (2001). Emotions and beliefs: How feelings influence thoughts? Cambridge University Press.

Hall, R. (1978). Stochastic implications of the life cycle-permanent income hypothesis. Journal of Political Economy, 86(6), 971-87. http://dx.doi.org/10.1086/260724

Hammond, R. K. (2000). Judgments under Stress. New York: Oxford University Press.

Hobfoll, S. E. (1989). Conservation of resources: A new attempt at conceptualizing stress. American Psychologist, 44, 513-24. http://dx.doi.org/10.1037/0003-066X.44.3.513

Hobfoll, S. E. (2001). The influence of culture, community, and the nested-self in the stress process: Advancing conservation of resource theory. Applied Psychology: An International Review, 50(3), 337-421. http://dx.doi.org/10.1111/1464-0597.00062

Hobfoll, S. E., \& Shirom, A. (2000). Conservation of resources theory: Applications to stress and management in the workplace. In R. T. Golembiewski (Ed.), Handbook of Organization Behavior (pp. 57-81). New York: Dekker.

Iacobucci, D., Saldanha, N., \& Deng, X. (2007). A meditation on mediation: Evidence that structural equations models perform better than regressions. Journal of Consumer Psychology, 17(2), 140-154. http://dx.doi.org/10.1016/S1057-7408(07)70020-7

Kahneman, D. (2003). Maps of bounded rationality: Psychology for behavioral economics. American Economic 
Review, 93, 1449-75. http://dx.doi.org/10.1257/000282803322655392

Kline, R. B. (2010). Principles and practice of structural equation modeling (3rd ed.). New York: Guilford Press.

Loewenstein, G. (2000). Emotions in economic theory and economic behavior. American Economic Review, 90, 2. http://dx.doi.org/10.1257/aer.90.2.426

Loewenstein, G., Weber, E. U., Hsee, C. K., \& Welch, N. (2001). Risk as feeling. Psychological Bulletin, 127(2), 267-286. http://dx.doi.org/10.1037/0033-2909.127.2.267

Mellers, B. A., \& Peter, A. M. (2001). Anticipated emotions as guides to choice. Current Directions in Psychological Science, 10, 6. http://dx.doi.org/10.1111/1467-8721.00151

Modigliani, F., \& Larry, C. S. (2004). The Chinese saving puzzle and the life-cycle hypothesis. Journal of Economic Literature, 145-170. http://dx.doi.org/10.1257/002205104773558074

Shefrin, H. H., \& Thaler, R. H. (1988). The behavioral life-cycle hypothesis. Economic Inquiry, 26, 609-643. http://dx.doi.org/10.1111/j.1465-7295.1988.tb01520.x

Simon, H. (1986). Rationality in psychology and economics. Journal of Business, 59(4), 209-224. http://dx.doi.org/10.1086/296363

Slovic, P., Peters, E., Finucane, M. L., \& Macgregor, D. G. (2005). Affect, risk and decision making. Health Psychology, 24, 35-40. http://dx.doi.org/10.1037/0278-6133.24.4.S35

Stern, S. (2009). Managing the mood is crucial when times are tough. Financial Times, 10.

Thaler, R. (1994). Psychology and savings policies. American Economic Review, 84(2), 186-92.

Tversky, A., \& Kahneman, D. (1974). Judgment under uncertainty: Heuristics and biases. Science, 185, 11241131. http://dx.doi.org/10.1126/science.185.4157.1124

Ünal-Karagüven, M. H. (2009). Psychological impact of an economic crisis: A conservation of resources approach. International Journal of Stress Management, 16, 177-94. http://dx.doi.org/10.1037/a0016840

\section{Notes}

Note 1 . Mental accounting refers to one's ability to subjectively frame transactions in one's mind involving intertemporal consumption or saving decisions (Shefrin \& Thaler 1988). During a financial crisis, individuals may be affected by job uncertainty and negative emotions or sentiments. As a result, they perceive or expect lower future incomes which drive them to save more for the future or, equivalently, consume less now.

Note 2. For a review of SEM, see Bollen (2010); Byrne (2010), and Kline (2010).

\section{Copyrights}

Copyright for this article is retained by the author(s), with first publication rights granted to the journal.

This is an open-access article distributed under the terms and conditions of the Creative Commons Attribution license (http://creativecommons.org/licenses/by/3.0/). 